\title{
Study of the Factors Associated with Home Delivery in a Situation of Free Care in Senegal
}

\author{
Adama Faye ${ }^{1 *}$, Anta Tal-Dia ${ }^{1}$, Daouda Faye ${ }^{2}$ \\ ${ }^{1}$ Instute of Health and Development, Cheikh Anta Diop University, Dakar, Sénégal \\ ${ }^{2}$ Dental Public Health Service, Cheikh Anta Diop University, Dakar, Sénégal \\ Email: ^adamfaye94@gmail.com, ^adama.faye@ucad.edu.sn
}

How to cite this paper: Faye, A., Tal-Dia, A. and Faye, D. (2017) Study of the Factors Associated with Home Delivery in a Situation of Free Care in Senegal. Open Journal of Epidemiology, 7, 326-336. https://doi.org/10.4236/ojepi.2017.74027

Received: September 24, 2017

Accepted: October 22, 2017

Published: October 25, 2017

Copyright $\odot 2017$ by authors and Scientific Research Publishing Inc. This work is licensed under the Creative Commons Attribution International License (CC BY 4.0).

http://creativecommons.org/licenses/by/4.0/

(c) (i) Open Access

\begin{abstract}
Introduction: Home delivery is still a health problem in Kolda (Senegal). The aim of this work is to study the factors associated with the place of delivery in a situation of free care delivery. Method: A descriptive and analytical cross-sectional study was carried out. Sampling was in two-stage clusters. The study focused on women who gave birth in the last 12 months. The data were collected during an individual interview at home. The collection focused on knowledge, attitudes and practices about delivery. Logistic regression was used to explore the determinants of childbirth at the level of health facility. Results: The average age was $25.4 \pm 6.5$ years. Among the interviewed women, education was reported in $35 \%$ of the women and $55 \%$ of women estimate that the closest health facility is within $5 \mathrm{~km}$ to their home. The time to get to the nearest health facility is less than 15 minutes for $39 \%$ of the interviewed women. The prevalence of home delivery was $43.5 \%$. Home delivery was related to the remoteness of the health facility (2.43 [1.75 - 3.37]) but also to incomplete antenatal care (2.52 [1.59 - 4.00]). Support groups highlighted difficulties of access to health facilities because of remoteness. Interviews revealed a lack of involvement of husbands in seeking care for women. Cultural barriers are still there. Conclusions: Despite the gratuity of delivery, the remoteness of health structures and socio-cultural factors are still barriers to access to care for pregnant women. These aspects must be taken into account in health policies. Multi-lateral interventions should be implemented to provide solutions for this health problem.
\end{abstract}

\section{Keywords}

Home Delivery, Free Care, Health Facility, Senegal 


\section{Introduction}

Maternal mortality is a major public health problem in sub-Saharan Africa where $50 \%$ of deaths occur. Its decline of $3 / 4$ between 2000 and 2015 constituted number Five of the Millennium Development Goals (MDGs) developed by UN [1]. However, a recent evaluation showed a very slow evolution of indicators in sub-Saharan Africa [2] with significant disparities between West and Central Africa [2]. In Senegal, by 2015, the maternal mortality ratio was 315 maternal deaths per 100,000 live births [3], while the target was 139, a difference of 253 points from the 2015 target [3].

Factors related to maternal and infant mortality are well documented in several studies [4]. Home delivery performed in poor conditions of asepsis is the cause of many complications, which may lead to maternal deaths. In most cases, home delivery is practised without the presence of qualified personnel. According to the WHO, a qualified personnel implies a midwife, a nurse or a doctor who have completed training and are authorized to practise. In fact, in developing countries a significant proportion of deliveries are performed by unskilled staff [5]. In Senegal, $26.8 \%$ of deliveries take place at home and the situation is worse in rural areas (39.2\%) [6]. This high rate of home deliveries is attributed to many factors. Among these are low socioeconomic status, women's illiteracy, lack of pregnancy monitoring, inaccessibility of health facilities and women's position in the society, which confers little decision-making power [7] [8] [9] [10]. That's why the Senegalese authorities have decided to make deliveries and caesarean sections free of charge in all health facilities and hospitals outside the region of Dakar [11]. The determinants of home delivery in a context of gratuity are not well documented [12] [13] [14]. The results vary from one country to another [12] [13] [14]. The aim of this work is to study the factors associated with the place of delivery in a situation of gratuity of delivery.

\section{Method}

\subsection{Setting}

Senegal, a resource-limited country, is located in West Africa. Its population is about 15 million inhabitants with a pyramidal health system. The country has 14 medical regions and 76 health districts. Kolda region is located in South Senegal. The population of Kolda region was about 662,455 inhabitants in 2013, with a density of 42.6 inhabitants per $\mathrm{km}^{2}$ [15]. Rural population represents $79 \%$. Thus more than half of the population of this region is under the age of 20 years. Concerning health infrastructure, it has: 1 hospital, 3 health centers, 42 health posts and 3 private health posts. However, these facilities are still far from some villages. In addition, sometimes some facilities are inaccessible, especially during the rainy season, where some villages remain isolated for more than three months.

\subsection{Design}

It was an estimate combining a quantitative method and a qualitative method. 
The quantitative study makes it possible to measure the extent of the phenomenon and associated factors. While the qualitative study has made it possible to understand the perceptions of women, husbands, mothers and community leaders at the place of childbirth and its determinants.

\subsection{Quantitative Method}

\section{Type of study}

It is a cross-sectional, descriptive and analytical study.

\section{Study population}

The study population is represented by women who gave birth in the last 12 months prior to the survey and reside in the Kolda region.

\section{Sampling}

The formula used to calculate the sample size is Schwartz.

$$
N=\left[Z \alpha^{2} \cdot P(1-P)\right] / e^{2}
$$

$Z \alpha:=1.96:$ reduced difference corresponding to the risk granted $(\alpha=5 \%, Z \alpha$ $=1.96)$

$P$ : proportion of women screened $=29.6 \%$

e: margin of error (set at $5 \%$ ).

The sample size thus calculated is 384 women. Taking into account a non-response rate of $5 \%$ and cluster effect 1.5 , we find ourselves with a size of 477 for each health district.

In each health district, the sample was divided into 24 Census District (RDs) of 20. In our study, RDs correspond to urban neighborhoods and rural villages. Initially we have listed all the neighborhoods in rural areas and municipalities in urban areas. An initial draw was made to identify the 24 districts and villages where the women to be interviewed will be selected. In each neighborhood or village, a first concession was made. In each concession, all women meeting the inclusion criteria are interviewed until they reach the size of the cluster.

\section{Data collect}

Data were collected by trained investigators. The collection of information was done by means of a questionnaire during an individual interview at the women's homes in the neighborhoods or in the villages after informed consent. The questionnaire included the following parts: socio-demographic characteristics, knowledge; women's attitudes and women's delivery practices. Planning for childbirth was assessed through five questions: knowledge of the place of delivery, the person who will perform the delivery, keeping money for emergencies, soap and clean linen. The score varied from 0 to 5 .

\section{Data analysis}

The dependent variable is the place of delivery. It defines as any woman who has given birth in a health facility. The qualitative variables were described as a proportion with their confidence interval and the quantitative variables as an average with their standard deviation. The analysis of the association between the dependent variable which is the place of delivery and the qualitative variables 
was carried out using a Pearson chi-square test.

A downward logistic regression was performed. The dependent variable is childbirth in the health facility. All independent variables with a $p$ of less than 0.25 [16] in the multivariate analysis were included in the multivariate analysis. The comparison of the models was done by the test of the likelihood ratio with a descending procedure. The suitability of the model was studied by the Hosmer and Lemeshow test.

\subsection{Qualitative Method}

In-depth interviews were conducted with the women and the support groups. The number of mothers in law, husbands and women to interview was set at 15 for each health district. Every time a woman was interviewed, her husband and her mother in law were too. We chose at random one woman for each CD. The sampling for the survey of traditional healers and religious leaders was exhaustive due to the reduced number of these actors for each CD. Interview guides were developed to collect information from mothers in law, husbands, religious leaders and traditional healers. Main developed topics were: Knowledge on ANC and delivery, perceptions on early first ANC and social and cultural consideration about pregnancy and delivery. Content analysis was made for the qualitative study.

\section{Results}

The age range of the 1444 women who responded to questions was $14-48$ years (mean $25.4 \pm 6.5$ years); $30 \%$ were younger than 20 years. The proportion of women with 1 child is $20 \%$, the proportion of children with 2 to 3 children is $33 \%$ and the proportion with more than 4 children is $47 \%$. Education was reported by $35 \%$ of the women. Fifty-two percent of women have income-generating activities and 51\% earn less than 50,000 FCFA per month. 55\% of women estimate that the health facility closest to their home is within $5 \mathrm{~km}$. The time to get to the nearest health facility is less than 15 minutes for $39 \%$ of the women surveyed.

Women knew the number of ANC recommended were $66 \%$. $79 \%$ of women knew the first prenatal consultation should be done before the 4 th month. $30 \%$ of women performed their first NPC in the first 3 months of pregnancy. Women who completed at least 4 ANC were $19 \%$.

Income generating activity, Household income and women's education were related to place of giving birth (Table 1). The frequency of delivery in a home health facility decreased with the availability of means of transport (Table 1). The distance from home to a health facility and the time spent to go the health facility was related to place of delivery (Table 1). Knowledge of NPC and preparation for childbirth are associated with home delivery.

The results of Table 2 shown that women who lived $5 \mathrm{~km}$ or more (2.43 [1.75 - 3.37]) and more than $15 \mathrm{mn}(1.54$ [1.09 - 2.17]) of a health facility had more 
Table 1. Determinants related to the achievement of delivery by a trained staff.

\begin{tabular}{|c|c|c|}
\hline & Home Delivery Yes (\%) & $p$ \\
\hline \multicolumn{3}{|l|}{ Personal Characteristics } \\
\hline \multicolumn{3}{|l|}{ Education level } \\
\hline None & $933(48.5)$ & 0.001 \\
\hline Primary or more & $498(35.7)$ & \\
\hline Household income & & 0.001 \\
\hline Less than 50,000 & $707(50.4)$ & \\
\hline 50,000 & $683(37.6)$ & \\
\hline Income generating activity & & 0.51 \\
\hline No & $741(45.1)$ & \\
\hline yes & $683(43.4)$ & \\
\hline Nearest health facility & & 0.001 \\
\hline Less than $5 \mathrm{~km}$ & $779(30.0)$ & \\
\hline $5 \mathrm{~km}$ or more & $683(60.9)$ & \\
\hline Time spent to go to the nearest health facility & & 0.001 \\
\hline Less than $15 \mathrm{mn}$ & $560(27.0)$ & \\
\hline $15 \mathrm{mn}$ or more & $873(55.1)$ & \\
\hline Parity & & 0.001 \\
\hline $0-3$ & $762(38.6)$ & \\
\hline More than 3 & $671(50.4)$ & \\
\hline Attendance to a counseling program & & 0.003 \\
\hline Yes & $753(40.4)$ & \\
\hline No & $678(48.2)$ & \\
\hline \multicolumn{3}{|l|}{ Knowledge } \\
\hline First ANC Period & & 0.001 \\
\hline Yes & $1110(39.1)$ & \\
\hline No & $323(58.5)$ & \\
\hline \multirow[t]{2}{*}{ Number of ANC during pregnancy } & & 0.001 \\
\hline & $907(39.5)$ & \\
\hline No & $469(50.1)$ & \\
\hline Role of iron folic-acid & & 0.001 \\
\hline Yes & $1327(41.9)$ & \\
\hline No & $96(72.9)$ & \\
\hline Advice and importance of ANC & & 0.001 \\
\hline Yes & $906(37.0)$ & \\
\hline No & $508(56.5)$ & \\
\hline
\end{tabular}




\section{Continued}

Advice and importance of the consumption

of iron folic-acid during 90 days

$\begin{array}{ll}\text { Yes } & 1194(39.5) \\ \text { No } & 234(66.7)\end{array}$

Advice and planning of delivery 0.001

$\begin{array}{cc}0 & 432(57.2) \\ 1-3 & 704(43.8) \\ 4-5 & 287(23.7)\end{array}$

Early achievement of ANC

Yes

329 (28.6)

No

$1104(47.8)$

Achievement of complete ANC

Yes

$202(15.4)$

No

$1231(48.8)$

Planning of delivery

0

$262(63.0)$

$1-3$

752 ( 46.7)

4 - 5

414 (27.1)

Table 2. Determinants of delivery by a trained staff (logistic model).

\begin{tabular}{|c|c|c|}
\hline & OR $[95 \% \mathrm{CI}]$ & $p$ \\
\hline \multicolumn{3}{|l|}{ Personal Characteristics } \\
\hline Education level & & 0.171 \\
\hline Primary or more & 1 & \\
\hline None & $1.22[0.92-1.62]$ & \\
\hline Household income & & 0.051 \\
\hline Less than 50,000 & 1 & \\
\hline 50,000 or more & $0.78[0.6-0.1]$ & \\
\hline Income generating activity & & 0.134 \\
\hline No & 1 & \\
\hline Yes & $1.22[0.94-1.57]$ & \\
\hline Nearest health facility & & 0.001 \\
\hline Less than $5 \mathrm{~km}$ & 1 & \\
\hline $5 \mathrm{~km}$ or more & $2.43[1.75-3.37]$ & \\
\hline Time spent to go to the nearest health facility & & 0.014 \\
\hline Less than $15 \mathrm{mn}$ & 1 & \\
\hline $15 \mathrm{mn}$ or more & $1.54[1.09-2.17]$ & \\
\hline
\end{tabular}




\section{Continued}

\section{Parity}

More than 3

$$
0 \text { - } 3
$$

Attendance to a counseling program

$$
\text { No }
$$$$
\text { Yes }
$$

Knowledge

First ACN Period

$$
\begin{aligned}
& \text { Yes } \\
& \text { No }
\end{aligned}
$$

Number of ANC during pregnancy

Yes

No

Role of iron folic-acid

Yes

No

Advice and importance of ANC

$$
\text { Yes }
$$$$
\text { No }
$$

Advice and importance of iron folic-acid taking during 90 days

Yes

No

Advice and planning of delivery

$$
\begin{gathered}
4-5 \\
1-3 \\
0
\end{gathered}
$$

\section{Practices}

Achievement of an early ANC

Yes

No

Achievement of a complete ANC

Yes

No

Planning of delivery

$$
\begin{aligned}
& 4-5 \\
& 1-3
\end{aligned}
$$$$
0
$$

0.067

1

$1.34[0.98-1.83]$

0.787

$0.96[0.73-1.27]$

$1.36[0.78-2.38]$

0.207

$1.2[0.9-1.59]$

0.028

$1.55[1.07-2.28]$

0.003

\section{1}

$1.02[0.7-1.48]$

$2.13[1.28-3.55]$
1

$1.09[0.78-1.52]$

1

$2.52[1.59-4.0]$

0.003

0.001
1

$1.59[1.02-2.47]$

$2.27[1.35-3.81]$ 
lucky to give birth with the help of a trained staff. Childbirth in the health facility increased with the level of childbirth planning (Table 2).

The results of the in-depth interviews show that:

- Inaccessibility of facilities is a real matter: "health facilities are far from homes and the roads are defective" asserts a mother in law.

- Deep Cultural believes: The planning of delivery is always confronted with cultural and traditional constraints, " $A$ woman does not have to plan her delivery, she must leave everything in the hands of God" says a husband, "We consider it is good and it's our destiny" explain a religious leader.

- Careless women: "Women are often surprised by labor, because they do not report early their pain" says mother in law.

- Lack of tools in facilities is pointed out: "in health facilities there is always something missing" Women.

In fact, the causes are related to the social realities, "some women conceal their health states, some husbands are ignorant, some families are not organized".

\section{Discussion}

The results of our study show that $43.5 \%$ of deliveries were performed in health facilities. The main factors associated are socio-demographic characteristics, knowledge and practices.

Home delivery performed by unskilled staff in unsanitary circumstances is one of the main causes of maternal mortality, contrary to the developed countries where delivery is carried out by trained staff. In Kolda, the proportion of home deliveries is higher than the national average of $26.8 \%$ [6].

Unlike the developed countries where home delivery is well planned by trained staff, in Africa, there are many problems. The results of our study show that this is mainly related to lack of delivery planning [5] [10] [17]. The planning of delivery allows women to be more involved in the management of pregnancy. In fact, identification of health facilities where delivery is to take place and the person who have to perform it allow the woman to have more information on her pregnancy.

The surprise effect of delivery is often responsible for home delivery [5]. It often happens that women themselves ignore the delivery period. Some women believe that childbirth is an unpredictable event [18] [19]. Particular emphasis should be place on the planning of delivery during ANC. But it implies that care givers be enough equipped but it is not often the case. These aspects should be taken into account during the training. The involvement of the Bajenou Gox (Neighborhood Sponsor) can be an alternative. However results show a low level of involvement of the latters.

Planning of delivery may be hampered by the position of the woman in the society. Her limited power of decision in household does not confer the ability to negotiate and to take some decisions [14] [20]. Planning of delivery is not often 
accepted in these societies, because it is considered as an interference with God's will. It is clear that to overcome these cultural barriers, it is important to involve husbands, religious and traditional leaders.

The situation is so alarming that the government has implemented a policy of free costs in caesarean delivery [11]. This policy of free costs delivery is a response to a logic of social justice that seeks to avoid the poorer to be marginalized and to be in permanent exclusion. In most countries where these policies have been implemented, they favored access to health care for the poor [21] [22] [23], and reduce social inequalities in health [12] by improving saving [24]. However, some writings show that they do not benefit to the poorest [13]. In some contexts, they have even benefit to the rich than the poor [13]. In order to benefit from this free care you have first to reach health facilities.

In our study the distance is a main factor of geographical inaccessibility [5] [7]. Similar results were found in Burkina Faso [14], in Kenya [25], in Ethiopia [26], in Tanzania [27] and in Nigeria [28]. Accessibility of health facility is a real problem in developing countries particularly in Africa. In rural areas one in three women has to do more than five kilometers to reach the nearest health service. This percentage rises to $80 \%$ for the nearest hospital because of the defective roads and inadequate means of transport. The resolution of these problems goes far beyond health and it is part of the broader framework of development.

Our study has certain limits. The prevalence of home delivery may be underestimated because only surviving women were interviewed. Measuring exposure after the outcome may lead to classification bias because women may be required to justify their behavior.

\section{Conclusion}

Results of this study show that the use of reproductive health services is related to environmental, economic, cultural and structural factors. Despite free childbirth, the remoteness of health structures and socio-cultural factors are still barriers to access to care for pregnant women. These aspects must be taken into account by health policies. Multisectoral interventions should be implemented to provide solutions to this health problem.

\section{References}

[1] Sachs, J.D. and McArthur, J.W. (2005) The Millennium Project, a Plan for Meeting the Millennium Development. Lancet, 365, 347-353.

[2] English, M., Nzinga, J., Mbindyo, P., Ayieko, P., Irimu, G. and Mbaabu, L. (2011) Explaining the Effects of a Multifaceted Intervention to Improve Inpatient Care in Rural Kenyan Hospitals-Interpretation Based on Retrospective Examination of Data from Participant Observation, Quantitative and Qualitative Studies. Implementation Science, 6, 124. https://doi.org/10.1186/1748-5908-6-124

[3] Ministry of Health and Welfare (Senegal) (2016) Evaluation of Neonatal and Emergency Needs in Senegal. $179 \mathrm{p}$.

[4] Khan, K.S., Wojdyla, D., Say, L., et al. (2006) WHO Analysis of Causes of Maternal 
Death: a Systematic Review. Lancet, 367, 1066-1074. https://doi.org/10.1016/S0140-6736(06)68397-9

[5] Bohren, M.A., Hunter, E.C., Munthe-Kaas, H.M., Souza, J.P., Vogel, J.P. and Gülmezoglu, A.M. (2014) Facilitators and Barriers to Facility-Based Delivery in Low- and Middle-Income Countries: A Qualitative Evidence Synthesis. Reproductive Health, 11, 71. https://doi.org/10.1186/1742-4755-11-71

[6] National Agency for Statistics and Demography (2012) Demographic Health Survey in Senegal 2010-2011. 367 p.

[7] Gabrysch, S. and Campbell, O.M. (2009) Still Too WAR to Walk, Literature Review of the Determinants of Delivery Service Use. BMC Pregnancy Childbirth, 9, 34.

[8] Faye, A., Faye, M., Bâ, I.O., Ndiaye, P. and Tal-Dia, A. (2010) Determinant Factors of the Delivery Place among Women Who Delivered at Least One Time in Health Structure (Sénégal). Rev Epidemiol Sante Publique, 58, 323-329.

[9] Faye, A., Manga, N.M., Seck, I., Niang, K., Leye, M.M., Diagne-Camara, M., Diongue, M., Ba, M., Ndiaye, P. and Tal-Dia A. (2011) Access to Intermittent Preventive Treatment (IPT) in a Situation of Free, Role of Economic Well Being. Bull. Bull Soc Pathol Exot, Uncomplete.

[10] Faye, A., Wone, I., Samb, O.M. and Tal-Dia, A. (2010) Study of Contributive Factors of Home Delivery in Senegal. Bulletin de la Société de pathologie exotique, 103, 246-251. https://doi.org/10.1007/s13149-010-0056-X

[11] Witter, S., Armar-Klemesu, M. and Dieng, T. (2008) National Fee Exemption Schemes for Deliverie: Comparing the Recent Experiences of Ghana and Senegal. In: Richard, F., Witter, S. and De Brouwere, V., Eds., Reducing the Financial Barriers to Access to Obstetric Care, Studies in Health Services Organisation and Policy series, ITG Press, Antwerp.

[12] McKinnon, B., Harper, S. and Kaufman, J.S. (2015) Who Benefits from Removing User Fees for Facility-Based Delivery Services? Evidence on Socioeconomic Differences from Ghana, Senegal and Sierra Leone. Social Science \& Medicine, 135, 117-123.

[13] Ganle, J.K., Parker, M., Fitzpatrick, R. and Otupiri, E. (2014) Inequities in Accessibility to and Utilisation of Maternal Health Services in Ghana after User-Fee Exemption: A Descriptive Study. International Journal for Equity in Health, 13, 89. https://doi.org/10.1186/s12939-014-0089-z

[14] De Allegri, M., Tiendrebéogo, J., Müller, O., Yé, M., Jahn, A. and Ridde, V. (2015) Understanding Home Delivery in a Context of User Fee Reduction: A Cross-Sectional Mixed Methods Study in Rural Burkina Faso. BMC Pregnancy Childbirth, 15, 330. https://doi.org/10.1186/s12884-015-0764-0

[15] National Agency for Statistics and Demography (2015) General Population Census of Senegal. $450 \mathrm{p}$.

[16] Hosmer, D.W. and Lemeshow, S. (2012) Applied Logistic Regression. Wiley-Interscience.

[17] Bedford, J., Gandhi, M., Admassu, M. and Girma, A. (2012) “A Normal Delivery Takes Place at Home": A Qualitative Study of the Location of Childbirth in Rural Ethiopia. Maternal and Child Health Journal, 17, 230-239. https://doi.org/10.1007/s10995-012-0965-3

[18] Magoma, M., Requejo, J., Campbell, O.M., Cousens, S. and Filippi, V. (2010) High ANC Coverage and Low Skilled Attendance in a Rural Tanzanian District: A Case for Implementing a Birth Planintervention. BMC Pregnancy Childbirth, 10, 1-12. https://doi.org/10.1186/1471-2393-10-13 
[19] Story, W.T., Burgard, S.A., Lori, J.R., Taleb, F., Ali, N.A. and Hoque, D.E. (2012) Husbands' Involvement in Delivery Care Utilization in Rural Bangladesh: A Qualitative Study. BMC Pregnancy Childbirth, 12, 28. https://doi.org/10.1186/1471-2393-12-28

[20] Moyer, C.A., Adongo, P.B., Aborigo, R.A., Hodgson, A., Engmann, C.M. and Devries, R. (2014) "It's up to the Woman's People": How Social Factors Influence Facility-Based Delivery in Rural Northern Ghana. Maternal and Child Health Journal, 18, 109-119. https://doi.org/10.1007/s10995-013-1240-y

[21] McKinnon, B., Harper, S., Kaufman, J.S. and Bergevin, Y. (2015) Removing User Fees for Facility-Based Delivery Services: A Difference-in-Differences Evaluation from Ten Sub-Saharan African Countries. Health Policy Plan, 30, 432-441. https://doi.org/10.1093/heapol/czu027

[22] Leone, T., Cetorelli, V., Neal, S. and Matthews, Z. (2016) Financial Accessibility and User Fee Reforms for Maternal Healthcare in Five Sub-Saharan Countries: A Quasi-Experimental Analysis. BMJ Open, 6, e009692. https://doi.org/10.1136/bmjopen-2015-009692

[23] Chama-Chiliba, C.M. and Koch, S.F. (2016) An Assessment of the Effect of User Fee Policy Reform on Facility-Based Deliveries in Rural Zambia. BMC Research Notes, 9, 504. https://doi.org/10.1186/s13104-016-2316-8

[24] Ridde, V., Agier, I., Jahn, A., Mueller, O., Tiendrebéogo, J., Yé, M. and De Allegri, M. (2015) The Impact of User Fee Removal Policies on Household Out-of-Pocket Spending: Evidence against the Inverse Equity Hypothesis from a Population Based Study in Burkina Faso. The European Journal of Health Economics, 16, 55-64. https://doi.org/10.1007/s10198-013-0553-5

[25] Danforth, E., Kruk, M., Rockers, P., Mbaruku, G. and Galea, S. (2009) Household Decision-Making about Delivery in Health Facilities: Evidence from Tanzania. Journal Health Population Nutrition, 27, 696-703.

[26] Gebrehiwot, T., Goicolea, I., Edin, K. and Sebastian, M.S. (2012) Making Pragmatic Choices: Women's Experiences of Delivery Care in Northern Ethiopia. BMC Pregnancy Childbirth, 12, 113. https://doi.org/10.1186/1471-2393-12-113

[27] Spangler, S.A. and Bloom, S.S. (2010) Use of Biomedical Obstetric Care in Rural Tanzania: The Role of Social and Material Inequalities. Social Science \& Medicine, 71, 760-768.

[28] Doctor, H.V., Findley, S.E., Ager, A., Cometto, G., Afenyadu, G.Y., Adamu, F. and Green, C. (2012) Using Community-Based Research to Shape the Design and Delivery of Maternal Health Services in Northern Nigeria. Reproductive Health Matters, 20, 104-112. 